\title{
Numerical Study of the Effect of the Reynolds Numbers on Thermal and Hydrodynamic Parameters of Turbulent Flow Mixed Convection Heat Transfer in an Inclined Tube
}

\author{
Farhad Vahidinia* - Mohadeseh Miri \\ University of Zabol, Department of Mechanical Engineering, Iran
}

A numerical investigation of the effect of the Reynolds number on the thermal and hydrodynamic parameters of mixed convection heat transfer of the water- $\mathrm{Al}_{2} \mathrm{O}_{3}$ nanofluid turbulent flow in an inclined circular channel is the subject of this article. The upper wall of the channel was under non-uniform heat flux and its lower part was isolated. The two-phase mixture model, the finite volume method, and the secondorder upstream difference scheme were used to solve the governing equations. After reviewing the results, it was found that by increasing Reynolds number, the convective heat transfer coefficient and shear stress increase, but the surface friction coefficient decreases. In the case of Nusselt number and the surface friction coefficient, some equations were extracted.

Keywords: mixed convection, inclined channel, turbulent flow, Reynolds number, surface friction coefficient

Highlights

- New correlations are proposed to calculate the Nusselt number and surface friction coefficient in an inclined tube which is a function of the Reynolds number and the angle of the tube from the horizon surface.

- $\quad$ The convective heat transfer coefficient increases with the increase of Reynolds number in an inclined tube.

- In an inclined tube, the surface friction coefficient of the length tube decreases when the Reynolds number is increased.

- By increasing volume fraction of the nanoparticles in an inclined tube, the convection heat transfer coefficient is increased.

\section{O INTRODUCTION}

Convective heat transfer in inclined tubes has long been considered. One of the most important applications of the inclined tube is their use in solar collectors and refrigerant distillation in condensers of heat transfer systems [1] to [3], since introducing the subject of adding nanoparticles to the base fluid to improve the efficiency of heat transfer systems, extensive studies were done both numerically and experimentally in horizontal tubes with different boundary conditions and various cross sections [4] to [6]. Saha and Paul [7] studied numerically turbulent flow forced convection heat transfer of two nanofluids and concluded that by increasing the Reynolds number, the Nusselt number increases. Azmi et al. [8] investigated experimental convection heat transfer of nanofluids turbulent flow under constant heat flux of the wall in a circular tube and indicated that the convection heat transfer coefficient increases with increasing the Reynolds Numbers in different volume fractions. Forced convective heat transfer of the water $/ \mathrm{Al}_{2} \mathrm{O}_{3}$ nanofluids turbulent flow was numerically investigated in a horizontal circular tube by Hejazian et al. [9]. They concluded that convective heat transfer coefficient increases with an increased Reynolds Numbers and volume fraction. Furthermore, these studies were widely investigated using nanofluids in the vertical tubes. [10] to [12].
He et al. [13] examined experimental heat transfer and flow behaviour in a vertical tube and concluded that by increasing the Reynolds Numbers, convective heat transfer coefficient and the flow pressure drop increase. Saberi et al. [14] investigated the numerically forced convective heat transfer of laminar flow with nanofluids under wall uniform heat flux in a vertical circular tube. They found that the convective heat transfer coefficient and the Nusselt number increase with increased Reynolds Numbers.

The inclined tubes also were selected for the studies [15] and [16]. Solar collectors are the most important devices which use of the inclined tubes to investigate heat transfer by using nanofluids is studied in them [17]. Numerical study of the mixed convective heat transfer water $/ \mathrm{Al}_{2} \mathrm{O}_{3}$ nanofluids laminar flow is conducted in the horizontal and inclined tubes by Akbari et al. [18]. They indicated that by increasing the inclination of the tube, surface friction coefficient continuously increases, but convective heat transfer coefficient has maximum value at an angle of $45^{\circ}$. Cimpean and Pop [19] investigated mixed convective heat transfer of laminar flow in an inclined channel and concluded that use of nanofluids increases heat transfer. Allahyari et al. [20] studied numerically mixed convective heat transfer of water $/ \mathrm{Al}_{2} \mathrm{O}_{3}$ nanofluids laminar flow with the wall non-uniform heat flux in an inclined circular tube; they concluded 
that convective heat transfer coefficient increases with enhancing nanoparticles volume fraction, but it decreases with increasing the tube angle from the horizontal surface. Mansour et al. [21] examined experimentally mixed convective heat transfer of water $/ \mathrm{Al}_{2} \mathrm{O}_{3}$ nanofluids laminar flow in an inclined tube. They observed that by increasing nanoparticles volume fraction and the Reynolds number, the Nusselt number decreases. On the other hand, the Nusselt number increases with increasing the Grashhof number. Investigating pressure drop of nanofluids laminar flow under the wall uniform heat flux studied experimentally in an inclined tube by Pirhayati et al. [22]. They made a conclusion that pressure drop increases with increasing volume fraction of nanoparticles, but increasing the inclination of the tube from the horizon from 0 degrees to 30 degrees for Reynolds number less than 170 , reduces the pressure drop. Derakhshan and Akhavan-Behabadi [23] used fin and flat inclined tubes to evaluate the flow characteristic, pressure drop, and friction coefficient by using MWCNT- oil nanofluid. They observed that by increasing the inclination of the tube from 0 degrees to 90 degrees, the pressure drop and friction coefficient increase. Also, pressure drop in the fin tubes is more than the flat tubes. Maré, et al. [24] also analyzed experimentally mixed convective heat transfer of laminar flow in a circular inclined tube.

In this paper, the effect of Reynolds number on thermal and hydrodynamic parameters including convective heat transfer coefficient, Nusselt number, surface friction coefficient is investigated numerically in mixed convective heat transfer $\mathrm{Al}_{2} \mathrm{O}_{3}$ /water nanofluids turbulent flow within an inclined copper tube under non-uniform heat flux of the upper wall and insulation of the lower wall by using two phase mixture model. According to the obtained numerical results, some equations are extracted to calculate the average Nusselt number and the wall surface friction coefficient in terms of Reynolds number changes and different inclinations of tube.

\section{MATHEMATICAL MODELING}

Turbulent mixed convection of a nanofluid consisting of water and $\mathrm{Al}_{2} \mathrm{O}_{3}$ in a horizontal circular tube with non-uniform heat flux on the upper wall and insulation in the lower wall has been considered. In order to discretize of governing equations the upstream difference scheme of second-order and finite volume method are used. Fig. 1 shows the considered geometrical configuration. The tube has a diameter of $0.01 \mathrm{~m}$ and a length of $1 \mathrm{~m}$. Tube thickness to diameter ratio of 0.1 is assumed. In this paper, the two phase mixture model is employed for the simulation. The nanofluid is a mixture of water and particles of $\mathrm{Al}_{2} \mathrm{O}_{3}$ and the size is uniform $32 \mathrm{~nm}$.

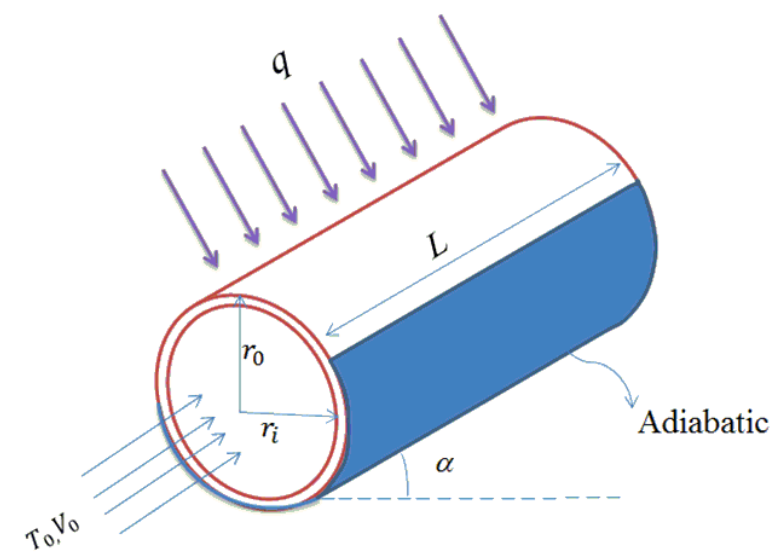

Fig. 1. Studied geometry (schematic of an inclined tube)

The conservation equations for steady state mixture model with assumption incompressible and Newtonian of flow are as follows [25]:

Continuity equation:

$$
\nabla \cdot\left(\rho_{m} \mathbf{V}_{m}\right)=0 .
$$

Conservation of momentum:

$$
\begin{aligned}
\nabla \cdot\left(\rho_{m} \mathbf{V}_{m} \mathbf{V}_{m}\right) & =-\nabla p_{m}+\nabla \cdot\left[\tau-\tau_{t}\right]- \\
& -\rho_{\text {eff }} \beta_{\text {eff }}\left(T-T_{0}\right) g+ \\
& +\nabla \cdot\left(\sum_{k=1}^{n} \phi_{k} \rho_{k} \mathbf{V}_{d r, k} \mathbf{V}_{d r, k}\right) .
\end{aligned}
$$

Conservation of energy:

$$
\nabla \cdot\left(\phi_{k} \mathbf{V}_{k}\left(\rho_{k} h_{k}+p\right)\right)=\nabla \cdot\left(\lambda_{e f f} \nabla T-C_{p} \rho_{m} \overline{v t}\right) .
$$

Conservation of energy:

$$
\nabla \cdot\left(\phi_{p} \rho_{p} \mathbf{V}_{m}\right)=-\nabla \cdot\left(\phi_{p} \rho_{p} \mathbf{V}_{d r, p}\right)
$$

where $\mathbf{V}_{m}$ and $\rho_{m}$ are defined as:

$$
\mathbf{V}_{m}=\frac{\sum_{k=1}^{n} \phi_{k} \rho_{k} \mathbf{V}_{k}}{\rho_{\text {eff }}}, \quad \rho_{m}=\sum_{k=1}^{n} \phi_{k} \rho_{k},
$$

In Eq. (2), $\mathbf{V}_{d r, k}$ is the drift velocity for the secondary phase $k$, i.e. the nanoparticles in the present study which is defined as:

$$
\mathbf{V}_{d r, k}=\mathbf{V}_{k}-\mathbf{V}_{m}
$$

and in Eq. (2), $\tau$ and $\tau_{t}$ are the viscous shear stress and turbulent shear stress which are defined as: 


$$
\tau=\mu_{m} \nabla \mathbf{V}_{m}, \quad \tau_{t}=-\sum_{k=1}^{n} \phi_{k} \rho_{k} \overline{v_{k} v_{k}},
$$

where $\mu_{m}$ is defined as:

$$
\mu_{m}=\sum_{k=1}^{n} \phi_{k} \mu_{k}
$$

$\mathbf{V}_{p f}$ is the slip velocity or relative velocity that defines as the velocity of a secondary phase $(p)$ relative to the velocity of the primary phase $(f)$.

$$
\mathbf{V}_{p f}=\mathbf{V}_{p}-\mathbf{V}_{f} \text {. }
$$

The drift velocity is related to the relative velocity which is defined as:

$$
\mathbf{V}_{d r, k}=\mathbf{V}_{p f}-\sum_{k=1}^{n} \frac{\phi_{k} \rho_{k}}{\rho_{m}} \mathbf{V}_{f k} .
$$

The relative velocity is determined from Eq. (9) proposed by Manninen et al. [26]:

$$
\mathbf{V}_{p f}=\frac{\rho_{p} d_{p}^{2}}{18 \mu_{f} f_{\text {drag }}} \frac{\left(\rho_{p}-\rho_{m}\right)}{\rho_{p}} \mathbf{a} .
$$

In this equation the drag function, $f_{\text {drag }}$ is calculated by Schiller and Naumann [27]:

$$
f_{\text {drag }}=\left\{\begin{array}{ll}
1+0.15 \operatorname{Re}_{p}{ }^{0.687}, & R e_{p} \leq 1000 \\
0.0183 \operatorname{Re}_{p}, & R e_{p} \geq 1000
\end{array}\right\} .
$$

The acceleration (a) in Eq. (11) is:

$$
\mathbf{a}=\mathbf{g}-\left(\mathbf{V}_{m} \cdot \nabla\right) \mathbf{V}_{m} .
$$

\section{TURBULENCE MODELING}

Turbulence is modeled with the Launder and Spalding [28] $k-\varepsilon$ turbulence model for the mixture. It is expressed by Eqs. (14) to (16):

$$
\begin{gathered}
\nabla \cdot\left(\rho_{m} \mathbf{V}_{m} k\right)=\nabla \cdot\left(\frac{\mu_{t, m}}{\sigma_{k}} \nabla k\right)+G_{k, m}-\rho_{m} \varepsilon, \\
\nabla \cdot\left(\rho_{m} \mathbf{V}_{m} \varepsilon\right)=\nabla \cdot\left(\frac{\mu_{t, m}}{\sigma_{\varepsilon}} \nabla k\right)+\frac{\varepsilon}{k}\left(c_{1} G_{k, m}-c_{2} \rho_{m} \varepsilon\right),
\end{gathered}
$$

where:

$$
\begin{aligned}
& \mu_{t, m}=\rho_{m} c_{\mu} \frac{k^{2}}{\varepsilon}, \quad G_{k, m}=\mu_{t, m}\left(\nabla V_{m}+\left(\nabla V_{m}\right)^{T}\right), \\
& c_{1}=1.44, c_{2}=1.92, c_{\mu}=.09, \sigma_{k}=1, \sigma_{\varepsilon}=1.3,
\end{aligned}
$$

where $c_{1}$ and $c_{2}$ are constants.

\section{BOUNDARY CONDITION}

The boundary conditions are expressed as follows:

- At inlet of tube $(Z=0)$ :

$$
V_{z}=V_{0}, \quad V_{\theta}=V_{r}=0, \quad T=T_{0}, \quad I=I_{0} .
$$

Turbulent intensity calculated based on the formula [29]:

$$
I_{0}=0.16(R e)^{\frac{-1}{8}} .
$$

- At the tube wall $\left(r=r_{0}\right)$ :

$$
\begin{aligned}
& 0 \leq \theta \leq \pi: \quad-\lambda_{s} \frac{\partial T_{s}}{\partial r}=q_{w}, \\
& \pi \leq \theta \leq 2 \pi: \quad-\lambda_{s} \frac{\partial T_{s}}{\partial r}=0 .
\end{aligned}
$$

- At the solid/fluid interface: $\left(r=r_{i}\right)$ :

$T_{w}=T_{n f}, \quad \lambda_{s} \frac{\partial T_{w}}{\partial r}=\lambda_{e f f} \frac{\partial T_{n f}}{\partial r}, \quad V_{z}=V_{r}=V_{\theta}=0$.

- At the tube outlet:

The diffusion fluxes are set to zero at the exit for all dependent variables and an overall mass balance correction is obeyed.

\section{NANOFLUID THERMO-PHISICAL PROPERTIES}

The physical properties are:

Effective density:

The nanofluid density is given by [30]:

$$
\rho_{m}=(1-\phi) \rho_{f}+\phi \rho_{p},
$$

where the volumetric concentration is given by:

$$
\phi=\frac{\rho_{f} \phi_{m}}{\rho_{f} \phi_{m}+\rho_{p}\left(1-\phi_{m}\right)},
$$

and where $\phi_{m}$ is the mass fraction.

An accurate equation is used for calculating the effective heat capacitance:

$$
\left(C_{p}\right)_{e f f}=\left[(1-\phi)\left(\rho C_{p}\right)_{f}+\phi\left(\rho C_{p}\right)_{p}\right] / \rho_{m}
$$

The thermal conductivity of the nanofluid is calculated from Chon et al. [31] correlation, which considers the Brownian motion and mean diameter of the nanoparticles.

$$
\begin{aligned}
\lambda_{\text {eff }} / \lambda_{f} & =1+64.7 \times \phi^{0.746} \times\left(d_{f} / d_{p}\right)^{0.369} \times \\
& \times\left(\lambda_{p} / \lambda_{f}\right)^{0.746} \times P r^{0.9955} \times R e^{1.2321},
\end{aligned}
$$




$$
\begin{aligned}
\lambda_{\text {eff }} / \lambda_{f} & =1+64.7 \times \phi^{0.746} \times\left(d_{f} / d_{p}\right)^{0.369} \times \\
& \times\left(\lambda_{p} / \lambda_{f}\right)^{0.746} \times \operatorname{Pr}^{0.9955} \times \operatorname{Re}^{1.2321},
\end{aligned}
$$

where $\operatorname{Pr}$ and $R e$ in Eq. (25) are defined as:

$$
\begin{gathered}
\operatorname{Pr}=\frac{\mu_{f}}{\rho_{f} \alpha_{f}}, \quad \operatorname{Re}=\frac{\rho_{f} B_{c} T}{3 \pi \mu^{2} l_{b f}}, \quad \mu=A \times 10^{\frac{B}{T-C}}, \\
C=140, \quad B=247, \quad A=2.414 \mathrm{e}^{-5} .
\end{gathered}
$$

$l_{b f}$ is the mean free path of water and $B_{c}$ is Boltzman constant $\left(B_{c}=1.3807 \times 10^{-23} \mathrm{~J} / \mathrm{K}\right)$.

Effective viscosity is calculated by the following equation proposed by Masoumi et al. [32] that considers the effects of volume fraction, density, and average diameter of nanoparticles and physical properties of the base fluid:

$$
\begin{gathered}
\mu_{e f f}=\mu f+\frac{\rho_{P} V_{B} d_{p}^{2}}{72 C \delta}, \\
V_{B}=\frac{1}{d_{p}} \sqrt{\frac{18 K_{b} T}{\pi \rho_{p} d_{p}}}, \quad \delta=\sqrt[3]{\frac{\pi}{6 \phi}} d_{p}, \\
C=\mu_{f}^{-1}\left[\left(c_{1} d_{p}+c_{2}\right) \phi+\left(c_{3} d_{p}+c_{4}\right)\right],
\end{gathered}
$$

where $c_{1}, c_{2}, c_{3}$ and $c_{4}$ are:

$$
\begin{array}{ll}
c_{1}=-0.000001133, & c_{2}=-0.000002721, \\
c_{3}=-0.00000009, & c_{4}=-0.000000393 .
\end{array}
$$

Thermal expansion coefficient proposed by Khanafer et al. [33]:

$$
\begin{aligned}
\beta_{\text {eff }}= & \beta_{\mathrm{p}} /\left(1+(1-\phi) \rho_{f} / \phi \rho_{p}\right) \beta_{f}+ \\
& +1 /\left(1+\phi \rho_{p} /(1-\phi) \rho_{f}\right) .
\end{aligned}
$$

\section{NUMERICAL METHOD AND VALIDATION}

In this work, the fluid enters the tube with a constant inlet temperature $T_{0}$ of $293 \mathrm{~K}$ and with uniform axial velocity of $V_{0}$. The Reynolds number for simulation and selection grid of 5000 is assumed. This set of coupled nonlinear differential equations is discretized with the control volume technique. For the convective and diffusive terms the second order upwind method is used while the SIMPLEC procedure is introduced for the velocity-pressure coupling. A structured nonuniform grid distribution has been used to discretize the computation domain. It is finer near the tube inlet and near the wall where the velocity and temperature gradients are large. Several different grid distributions have been tested to ensure that the calculated results are grid independent.
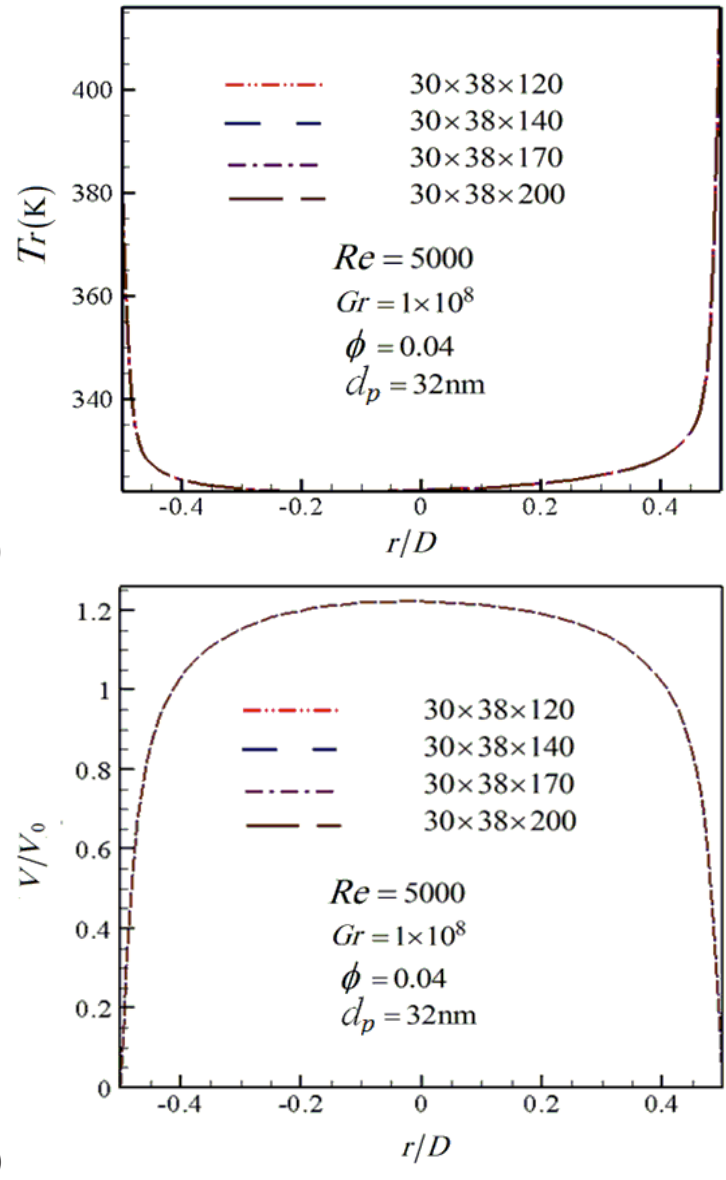

Fig. 2. Grid independence test: a) fully developed temperature, b) centerline axial velocity

The selected grid for the present calculations consisted of 170, 30 and 38 nodes, respectively, in the axial, radial and circumferential directions.

As shown in Fig. 2 increasing the grid numbers do not significantly change the velocity and temperature of the nanofluid. Other axial and radial profiles have also been verified to be sure the results are grid independent.

In order to demonstrate the validity and also precision of the model and numerical procedure, comparisons with the available experimental and numerical simulation have been done. As it is shown in Fig. 3, good agreements between the results are observed.

Fig. 3a shows the comparison of the calculated results with the results obtained by Gnielinski and 
Sruher [34] and experimental results obtained by Wusiman et al. [35].

Another comparison has also been performed with the experimental results obtained by Torii [36]. (See Fig. 3b).

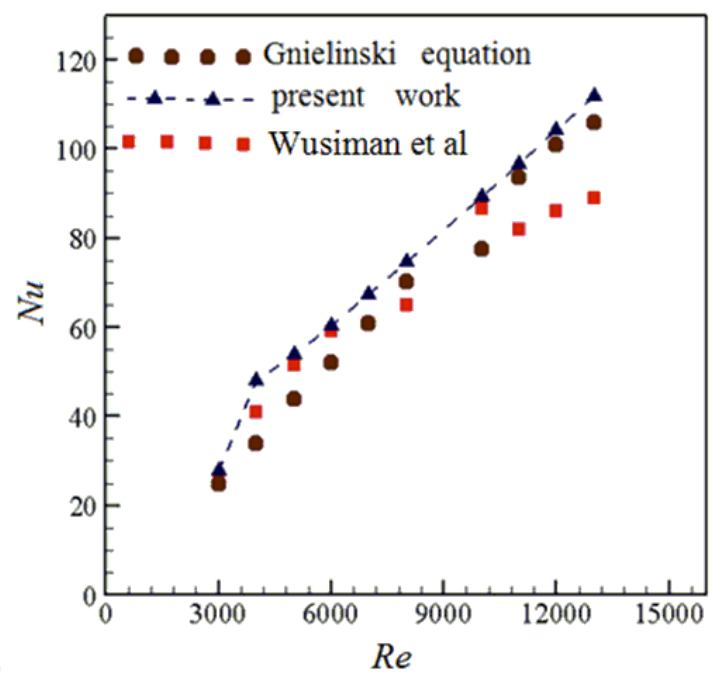

a)

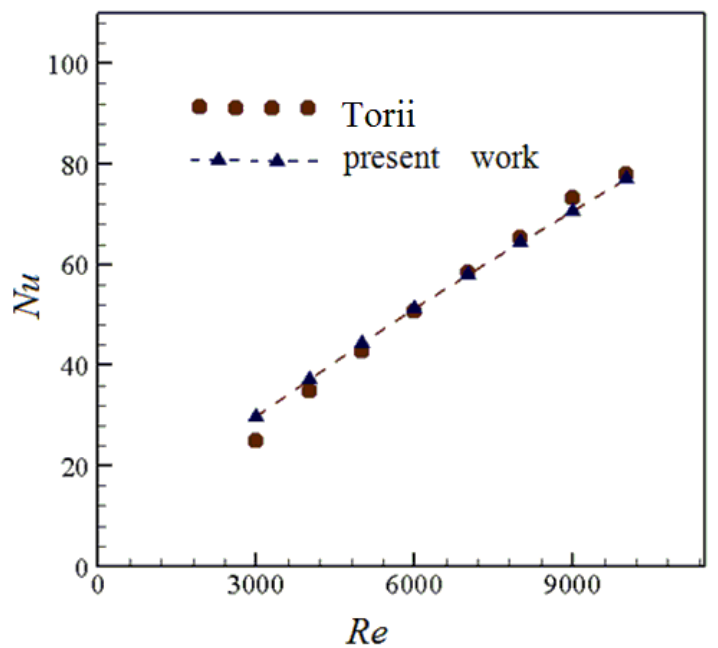

Fig. 3. Comparison of the axial evolution of Nu in a horizontal tube with the results obtained by a) Gnielinski and Sruher [34] and Wusiman et al. [35]; and b) Torii [36]

\section{RESULTS}

One important factor in the study of mixed convective heat transfer of the turbulent flow is to investigate the Reynolds number changes and its effect on thermal and hydrodynamic parameters. The Reynolds number, the volume fraction of nanoparticles and Grashof number are considered 4000 to $6000,4 \%$, $G r=1 \times 10^{8}$ respectively. In this study, the inclination of the tube from horizon is considered 45 degrees

and flow of Aluminum oxide/water nanofluids is investigated. Considering that the Reynolds number is the ratio of inertial forces to viscosity forces, with constant volume fraction of the nanoparticles and thus constant viscosity forces, increase or decrease of the Reynolds number will increase or decrease the inertial forces. On the other hand, the Richardson number was defined as the ratio of the Grashof number to the square of Reynolds number in reference [20] and [38]. According to the reference [37], if the above ratio is $\left(G r / R e^{2} \ll 1\right)$, there will be forced convection heat transfer and we can neglect the effect of natural convection. If, $\left(G r / R e^{2} \gg 1\right)$, we will have natural convection heat transfer and can neglect the effect of forced convection. Regarding this subject, the references [20], [25] and [38] deal with the study of mixed convection heat transfer. Reference [38], shows the mixed convection heat transfer of nanofluid in laminar flow at Richardson numbers of $(R i=0.33$, 1.66 and 5) in a horizontal tube and reference [20], studied this matter in an inclined tube. Reference [25], also studied the mixed convection heat transfer of nanofluid of turbulent flow in a curved horizontal tube at similar Richardson numbers. As can be seen in references [20], [25] and [38], we will have mixed convection heat transfer at Richardson number $(R i=$ 4) that is assumed in the present paper. It means that we will have both the effects of buoyancy forces and inertia forces.

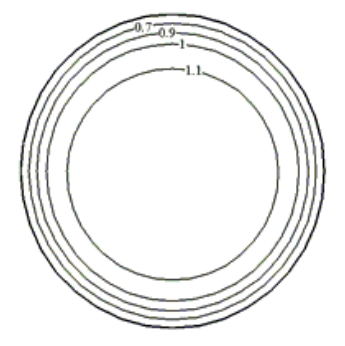

$$
R e=5000 \quad R e=4000
$$
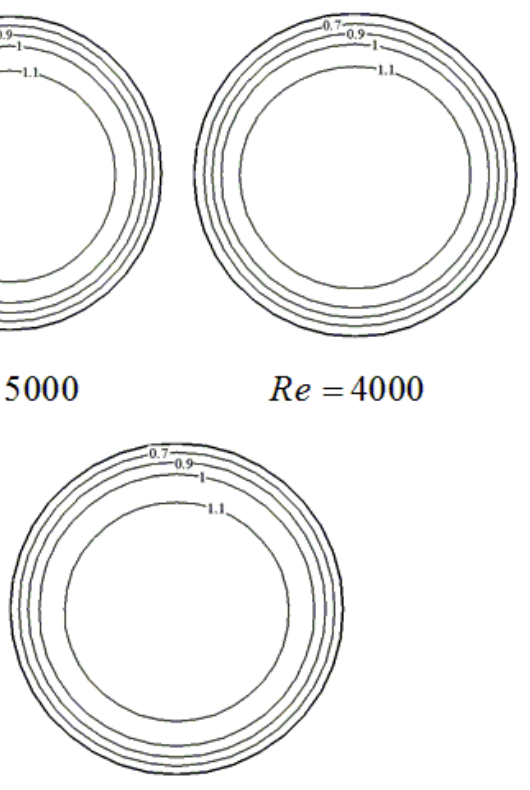

$$
R e=6000
$$

Fig. 4. Dimensionless axial velocity contours in the radial direction for different Reynolds numbers of $Z / D=94, \phi=0.04$ and $\alpha=45$ 
Fig. 4 indicates dimensionless axial velocity contours for Grashof number $G r=1 \times 10^{8}$ at $4 \%$ volume fraction in different Reynolds numbers and an angle of 45 degrees from horizon.

As figure shows, dimensionless axial velocity contours become longer in the vertical direction with increase of the Reynolds number and it will not have any movement to the up or down of the wall.

Fig. 5 shows dimensionless axial velocity profile in an inclined tube at an angle of 45 degrees from horizon at different Reynolds numbers. As can be seen, in this case velocity profile becomes more uniform with increasing the Reynolds number. Fig. 6 indicates dimensionless axial velocity profile on the tube centerline in an inclined tube at an angle of 45 degrees from horizon at different Reynolds numbers. It is shown in this figure that flow rate is reached to a maximum value after the tube inlet and then is developed. The reason for this is that after the tube inlet, the growth of the tube boundary layer causes contraction and conducts flow towards the tube centerline, thus increases the velocity on the tube centerline. By increasing the Reynolds number, the velocity maximum point inclines down, since by increasing the Reynolds number, the axial momentum and turbulence production in the flow direction increase.

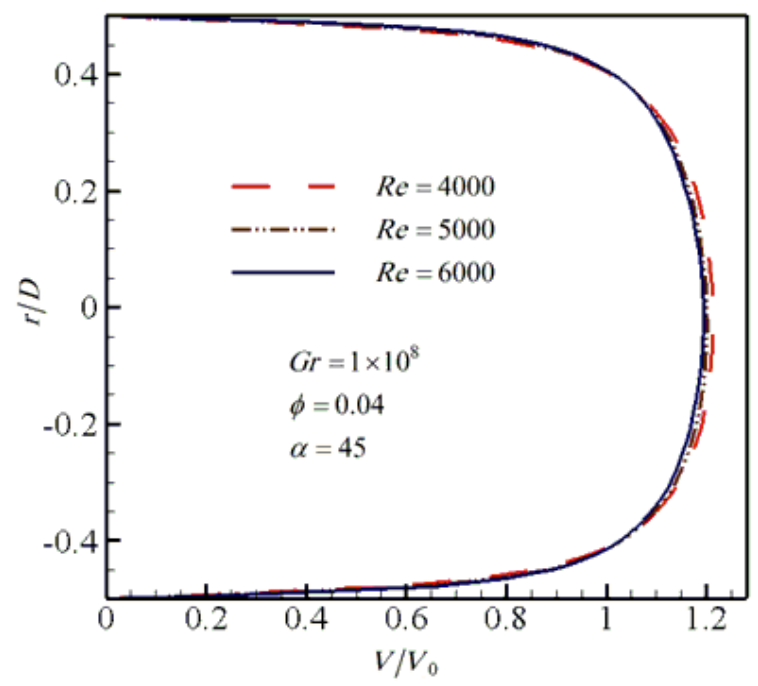

Fig. 5. Dimensionless axial velocity profile in the radial direction for different Reynolds numbers of Z/D $=94$

The dimensionless axial velocity maximum and the amount of development reduce with increase of Reynolds number and the most important reason for this process is that the velocity profile become more uniform with the increase of Reynolds number.

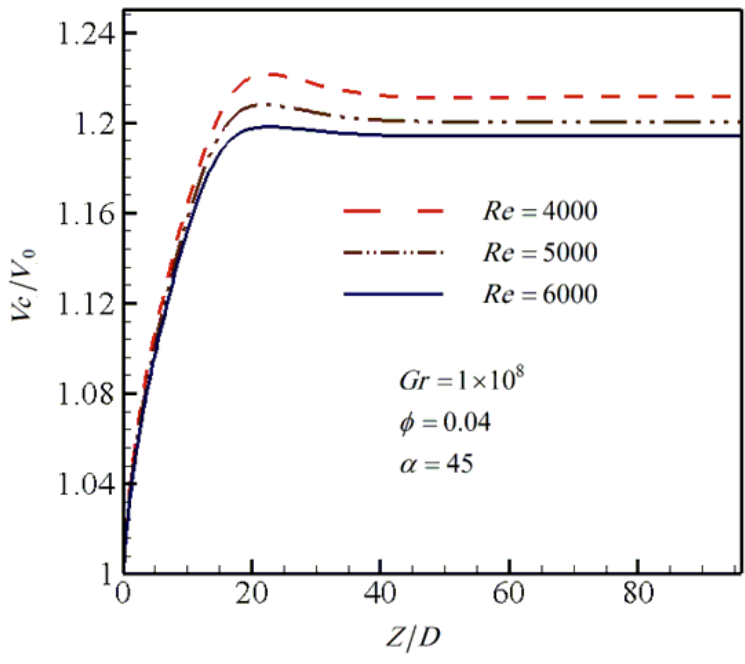

Fig. 6. Dimensionless axial velocity profile in the tube centerline for different Reynolds numbers

Fig. 7 displays dimensionless temperature contours on $Z / D=94$ of an inclined tube with an angle of 45 degrees from horizon, constant Grashof number $G r=1 \times 10^{8}$, and $4 \%$ volume fraction at different Reynolds numbers. As can be seen in the figure, dimensionless temperature decreases with the increase of the Reynolds number. At the end of the tube at high Reynolds, fluid has enough time to get the heat. So the temperature contours are asymmetric.
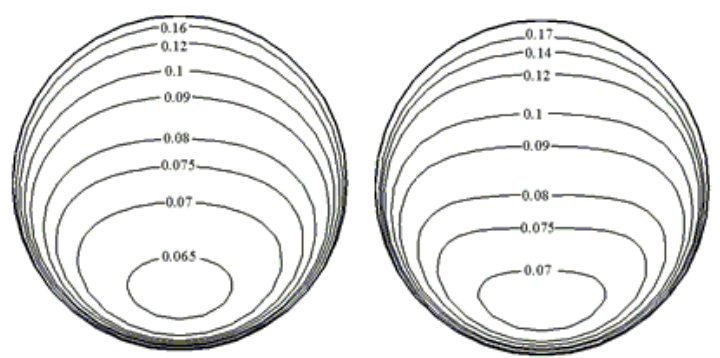

$$
R e=5000 \quad R e=4000
$$

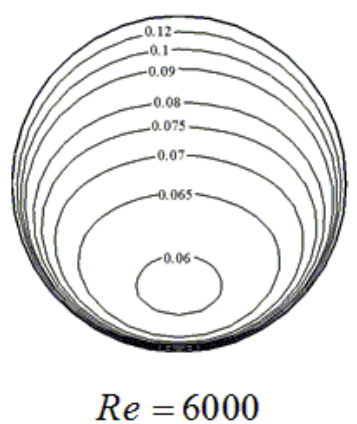

Fig. 7. Dimensionless temperature contours for different Reynolds numbers of $Z / D=94, \phi=0.04, \mathrm{Gr}=1 \times 10^{8}$ and $\alpha=45$ 
Fig. 8 shows the turbulent kinetic energy profile on $Z / D=94$ of an inclined tube with an angle of 45 degrees from horizon at Grashof number $G r=1 \times 10^{8}$, and different Reynolds numbers. In this figure, the turbulent kinetic energy increases with increase of the Reynolds number and its main reason will be increase of velocity and turbulences. Fig. 9 indicates changes of convective heat transfer coefficient in the tube dimensionless length within an inclined tube at different Reynolds numbers. At the beginning of the tube after the inlet, the convective heat transfer coefficient is very high due to the proximity of the wall temperature and the fluid bulk temperature. This coefficient reaches to the minimum value with distance from the inlet and there is maximum temperature difference between the wall temperature and the fluid bulk temperature in this area. Then, it remains constant due to the same temperature difference in the developed area. As observed in this figure, convective heat transfer coefficient increases with the increase of Reynolds number and its main reason is the increase of turbulent kinetic energy and turbulences.

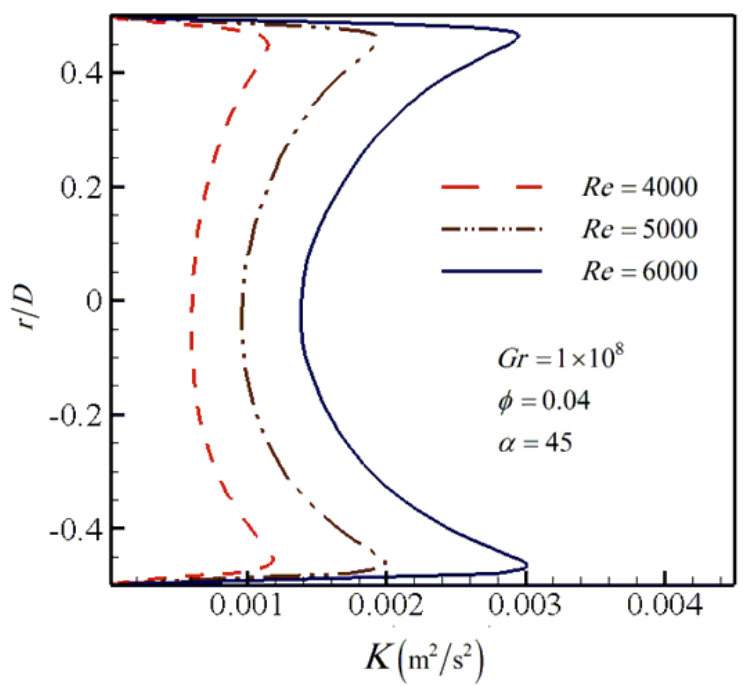

Fig. 8. Turbulent kinetic energy profiles in the radial direction for different Reynolds numbers of Z/D $=94$

Fig. 10 displays the shear stress changes in the dimensionless length of an inclined tube with Grashof number $G r=1 \times 10^{8}$, and solid to liquid volume ratio of $4 \%$ at different Reynolds numbers. By increasing Reynolds number in a constant volume fraction, the flow rate increases resulting in increased velocity gradient. With increase of the velocity gradient and constant viscosity, the shear stress increases. Fig. 11 shows changes of surface friction coefficient in the

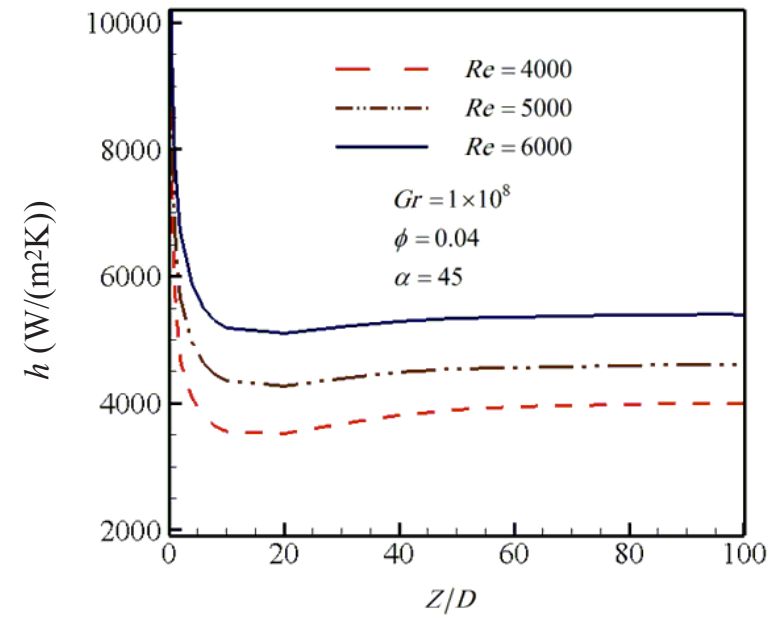

Fig. 9. Changes of convective heat transfer coefficient for different Reynolds numbers in the tube dimensionless length

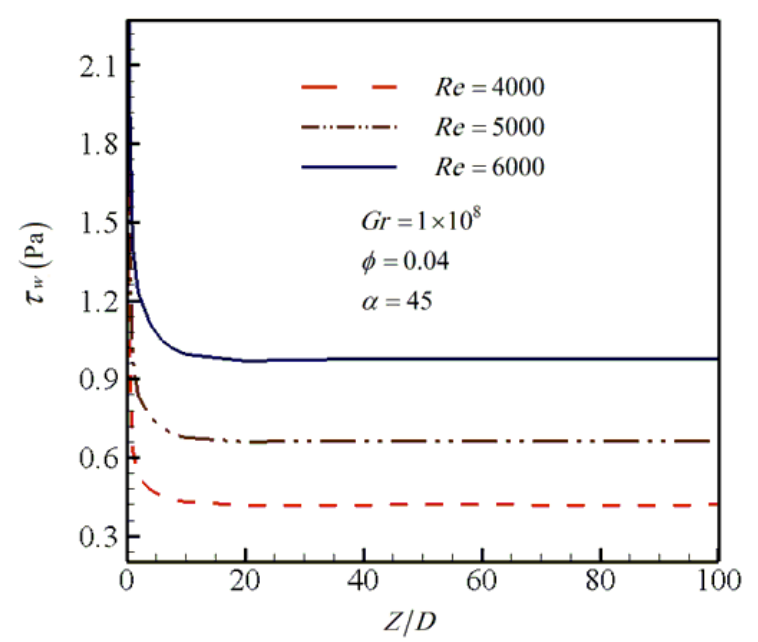

Fig. 10. Changes of shear stress in the dimensionless length of the tube for different Reynolds numbers

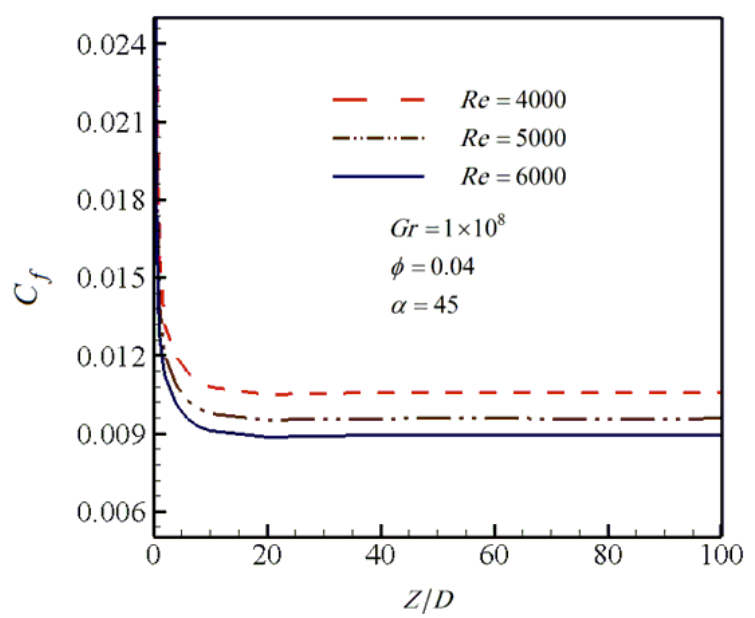

Fig. 11. Changes of surface friction coefficient in dimensionless length of the tube for different Reynolds numbers 
tube dimensionless length within a horizontal inclined tube with Grashhof number $G r=1 \times 10^{8}$, and solid to liquid volume ratio of $4 \%$ at different Reynolds numbers. By increasing the Reynolds number, the surface friction coefficient of the tube decreases; this is because of interactions between shear stress and flow rate changes with increase of the Reynolds number.

Fig. 12 shows changes of convection heat transfer coefficient in dimensionless length of the tube at Grashof number $G r=1 \times 10^{8}$, Reynolds number $R e=$ 5000 , and with an angle of 45 degrees from horizon in different volume fraction of solid-liquid particles. As can be seen in this figure, by increasing volume fraction of the nanoparticles in an inclined tube, the convection heat transfer coefficient increases; the main reason is the fluid's thermo-physical characteristics improving with increase of nanoparticles volume fraction.

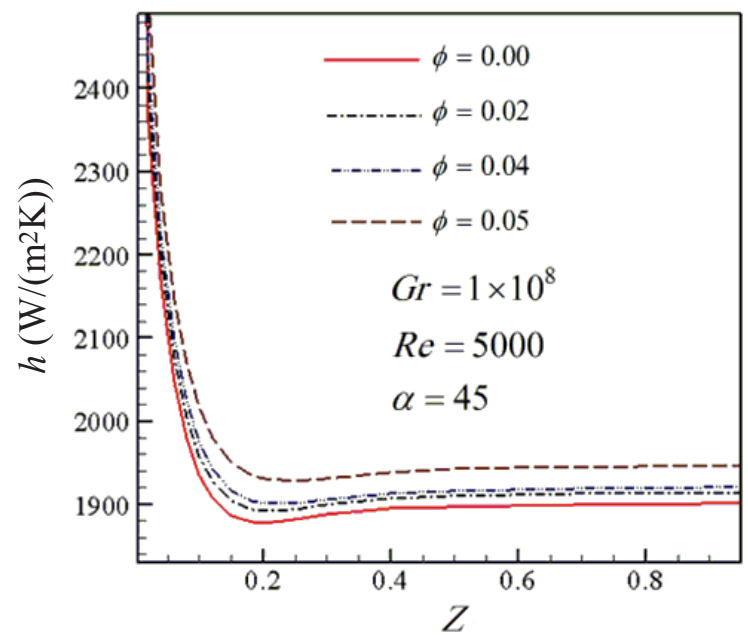

Fig. 12. Changes of convective heat transfer coefficient in dimensionless length of the tube for different volume fraction

\section{EXTRACTED EQUATIONS FROM THIS STUDY}

The behavior of nanofluids heat transfer depends on various parameters such as thermal conductivity, convective heat transfer coefficient, viscosity, heat capacity, angle of the tube from horizon, and volume fraction of nanoparticles. Considering investigation of the hydrodynamic and thermal behavior of nanofluids in an inclined tube, the following equations are obtained to calculate average Nusselt number and surface friction coefficient of the wall.

The following equations are for Nusselt number and surface friction coefficient in an inclined tube which is a function of the Reynolds number and angle of the tube from the horizon surface. In the volume fraction $\phi=0.04$ for the developed area, it obtains:

$$
\begin{aligned}
N u_{a v} & =0.115 \operatorname{Re}^{0.801}(34.408+\alpha)^{-0.189}, \\
C_{f} & =0.31 \operatorname{Re}^{-0.391}(0.684+\alpha)^{0.011} .
\end{aligned}
$$

Fig. 13 displays changes of the average Nusselt number in terms of the Reynolds number in different angles within an inclined tube. As observed, the Nusselt number increases with increase of the Reynolds number. On the other hand, by increasing angle of the tube from horizon, the Nusselt number decreases in a certain Reynolds number. By comparing the obtained values from the Eq. (30) and numerical

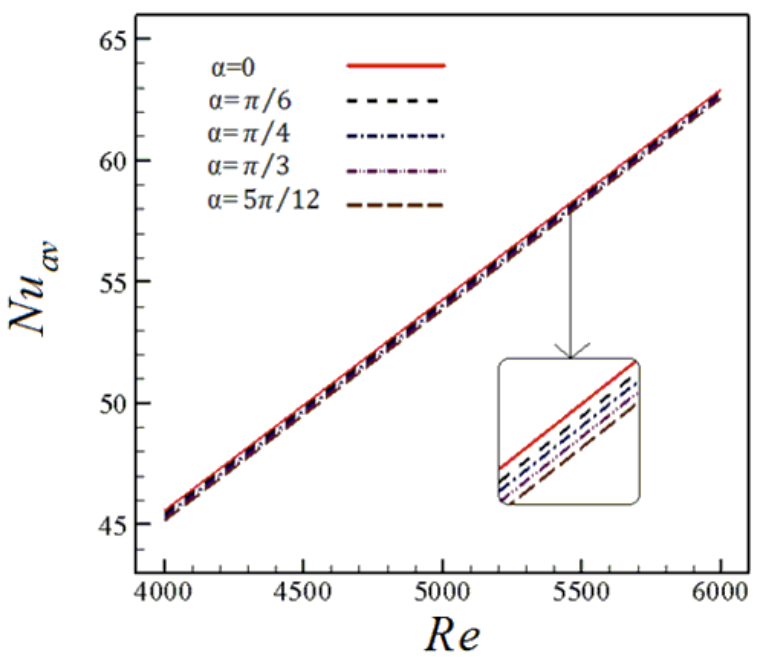

Fig. 13. Changes of average Nusselt number in terms of Reynolds number for different inclinations of tube

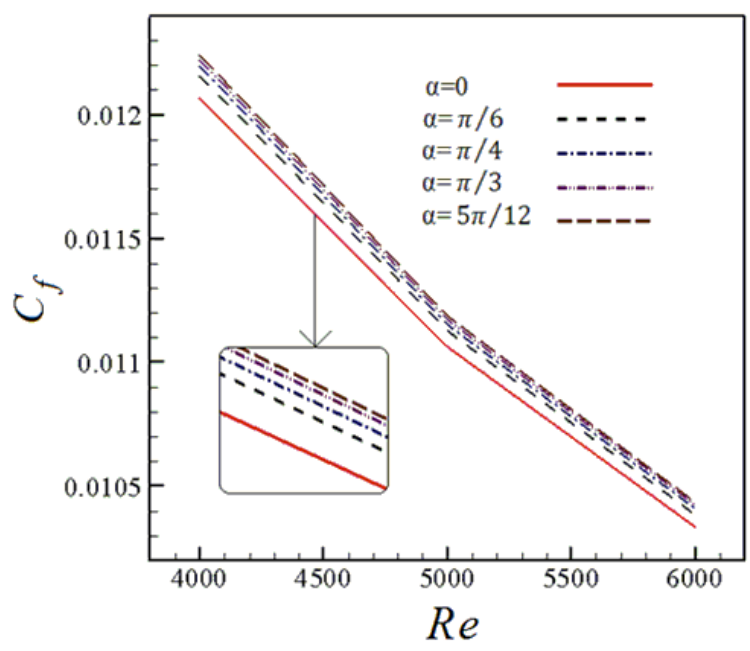

Fig. 14. Changes of surface friction coefficient in terms of Reynolds number for different inclinations of tube 
data of the thesis, the correlation coefficient is equal to $\mathrm{R}^{2}=0.9998$ for the Eq. (30).

Fig. 14 indicates changes of surface friction coefficient in terms of the Reynolds number in different angles within an inclined tube. As can be seen, by increasing the Reynolds number, the surface friction coefficient decreases. On the other hand, by increasing angle of the tube from horizon, the surface friction coefficient increases in a certain Reynolds number. By comparing the obtained values from the Eq. (31) and numerical data of the thesis, the correlation coefficient is equal to $\mathrm{R}^{2}=0.9997$ for the Eq. (31).

\section{CONCLUSION}

In this paper, the effect of Reynolds number on thermal and hydrodynamic characteristics of the nanofluids turbulent flow mixed convective heat transfer within an inclined tube is numerically studied with non-uniform heat flux on the upper wall of the tube and insulation in the lower wall by using two phase mixture model. The results indicated that dimensionless axial velocity becomes more uniform with increase of the Reynolds number in a certain Grashof number and constant volume fraction. By increasing the Reynolds number, the axial momentum increases and turbulence produces in the flow direction. Dimensionless axial velocity maximum and the amount of development decreases with increase of the Reynolds number and the most important reason of this process is that the velocity profile becomes more uniform with increase of the Reynolds number. By increasing the Reynolds number, the turbulent kinetic energy increases and this is because of increase of velocity and thus the turbulences in the fluid. By increasing Reynolds number, the convective heat transfer coefficient and shear stress increase but the surface friction coefficient decreases.

\section{NOMENCLATURES}

a acceleration $\left[\mathrm{ms}^{-2}\right]$

$C_{f}$ average skin friction coefficient

$C_{p}$ specific heat of the fluid $\left[\mathrm{Jkg}^{-1} \mathrm{~K}^{-1}\right]$

$d_{f}$ molecular diameter of base fluid [nm]

$d_{p}$ nanoparticle diameter $[\mathrm{nm}]$

$D$ tube diameter $[\mathrm{m}]$

$g$ gravity acceleration $\left[\mathrm{ms}^{-2}\right]$

Gr Grashof number

$h$ average convective heat transfer coefficient $\left[\mathrm{Wm}^{-2} \mathrm{~K}^{-1}\right]$

$K \quad$ turbulent kinetic energy $\left[\mathrm{m}^{2} \mathrm{~s}^{-2}\right]$
$L \quad$ channel length $[\mathrm{m}]$

$n$ number of phase

$p$ pressure $[\mathrm{Pa}]$

$q \quad$ average wall heat flux $\left[\mathrm{Wm}^{-2}\right]$

$r$ radial coordinate $[\mathrm{m}]$

Re Reynolds number

$t \quad$ fluctuating temperature $[\mathrm{K}]$

$T$ temperature $[\mathrm{K}]$

$V \quad$ velocity $\left[\mathrm{ms}^{-1}\right]$

$Z$ axial coordinate $[\mathrm{m}]$

Greek letters

$\alpha$ Thermal diffusivity and inclination of tube $\left[\mathrm{Wm}^{-2}\right]$

$\beta \quad$ Volumetric expansion coefficient $\left[\mathrm{K}^{-1}\right]$

$\varepsilon \quad$ Dissipation of turbulent kinetic energy $\left[\mathrm{m}^{2} \mathrm{~s}^{-1}\right]$

$\theta$ Angular coordinate

$\phi$ particle volume concentration

$\lambda$ thermal conductivity of the fluid $\left[\mathrm{Wm}^{-1} \mathrm{~K}^{-1}\right]$

$\mu \quad$ fluid dynamic viscosity $\left[\mathrm{Kgm}^{-1} \mathrm{~S}^{-1}\right]$

$v \quad$ kinematic viscosity $\left[\mathrm{m}^{2} \mathrm{~s}^{-1}\right]$

$\rho \quad$ fluid density $\left[\mathrm{Kgm}^{-3}\right]$

$\tau$ shear stress $[\mathrm{Pa}]$

Subscript

$b$ bulk value

$d r \quad$ drift

eff effective

$f$ primary phase

$k \quad k^{\text {th }}$ phase

$m$ mixture

$n f$ nanofluid

$p$ particle, secondary phase

$s$ solid

$t$ turbulent

$w$ wall

0 inlet condition

\section{REFERENCES}

[1] Mozafari, M., Akhavan-Behabadi, M.A., Qobadi-Arfaee, H., Hanafizadeh, P., Fakoor-Pakdaman, M. (2015). Experimental study on condensation flow patterns inside inclined U-bend tubes. Experimental Thermal and Fluid Science, vol. 68, p. 276-287, D0I:10.1016/j.expthermflusci.2015.05.003.

[2] Garcia, A., Martin, R.H., Perez-Garcia, J. (2013). Experimental study of heat transfer enhancement in a flat-plate solar water collector with wire-coil inserts. Applied Thermal Engineering, vol. 61, no. 2, p. 461-468, Dol:10.1016/j. applthermaleng.2013.07.048.

[3] Meyer, J.P., Dirker, J., Adelaja, A.O. (2014). Condensation heat transfer in smooth inclined tubes for R134a at different saturation temperatures. International Journal of Heat and Mass Transfer, vol. 70, p. 515-525, Dol:10.1016/j. ijheatmasstransfer.2013.11.038. 
[4] Sokhansefat, T., Kasaeian, A.B., Kowsary, F. (2014). Heat transfer enhancementin parabolic trough collector tube using Al203/synthetic oil nanofluid. Renewable and Sustainable Energy Reviews, vol. 33, p. 636-644, D0l:10.1016/j. rser.2014.02.028.

[5] Derakhshan, M.M., Akhavan-Behabadi, M.A., Mohseni, S.G. (2015). Experiments on mixed convection heat transfer and performance evaluation of MWCNT-Oil nanofluid flow in horizontal and vertical microfin tubes. Experimental Thermal and Fluid Science, vol. 61, p. 241-248, D0l:10.1016/j. expthermflusci.2014.11.005.

[6] Moghadassi, A., Ghomi, E., Parvizian, F. (2015). A numerical study of water based Al203 and Al203-Cu hybrid nanofluid effect on forced convective heat transfer. International Journal of Thermal Sciences, vol. 92, p. 50-57, D0l:10.1016/j. ijthermalsci.2015.01.025.

[7] Saha, G., Paul, M.C. (2015). Heat transfer and entropy generation of turbulent forced convection flow of nanofluids in a heated pipe. International Communications in Heat and Mass Transfer, vol. 61, p. 26-36, D0I:10.1016/j. icheatmasstransfer.2014.11.007.

[8] Azmi, W.H., Sharma, K.V., Sarma, P.K., Mamat, R., Najafi, G. (2014). Heat transfer and friction factor of water based TiO2 and SiO2 nanofluids under turbulent flow in a tube. International Communications in Heat and Mass Transfer, vol. 59, p. 30-38, DOI:10.1016/j.icheatmasstransfer.2014.10.007.

[9] Hejazian, M., Moraveji, M.K., Beheshti, A. (2014). Comparative study of Euler and mixture models for turbulent flow of Al203 nanofluid inside a horizontal tube. International Communications in Heat and Mass Transfer, D0l:10.1016/j. icheatmasstransfer.2014.01.022.

[10] Aminfar, H., Mohammadpourfard, M., Narmani Kahnamouei, Y. (2011). A 3D numerical simulation of mixed convection of a magnetic nanofluid in the presence of non uniform magnetic field in a vertical tube using two phase mixture model. Journal of Magnetism and Magnetic Materials, vol. 323, no. 15, p. 1963-1972, D0I:10.1016/J.jmmm.2011.02.039.

[11] Behzadmehr, A., Laneville, A., Galanis, N. (2008). Experimental study of onset of laminar-turbulent transition in mixed convection in a vertical heated tube. International Journal of Heat and Mass Transfer, vol. 51, no. 25-26, p. 5895-5905, D0I:10.1016/j.ijheatmasstransfer.2008.04.005.

[12] Behzadmehr, A., Galanis, N., Nguyen, C.T. (2006). Predicted effects of inlet turbulent intensity on mixed convection in vertical tubes with uniform wall heat flux. International Journal of Thermal Sciences, vol. 45, no. 5, p. 433-442, DOI:10.1016/j.jthermalsci.2005.08.004.

[13] He, Y., Jin, Y., Chen, H., Ding, Y., Cang, D., Lu, H. (2007). Heat transfer and flow behaviour of aqueous suspensions of TiO2 nanoparticles (nanofluids) flowing upward through a vertical pipe. International Journal of Heat and Mass Transfer, vol. 50, no. 11-12, p. 2272-2281, D0l:10.1016/j. ijheatmasstransfer.2006.10.024.

[14] Saberi, M., Kalbasia, M., Alipourzadeh, A. (2013). Numerical Study of Forced Convective Heat Transfer of Nanofluids inside a Vertical Tube. International Journal of Thermal Technologies, vol. 3, no. 1, p. 10-15.
[15] Mansour, R.B., Galanis, N., Nguyen, C.T. (2009). Developing laminar mixed convection of nanofluids in an inclined tube with uniform wall heat flux. International Journal of Numerical Methods for Heat \& Fluid Flow, vol. 19, no. 2, p. 146-164, DOI:10.1108/09615530910930946.

[16] Busedra, A.A., Soliman, H.M. (2000). Experimental investigation of laminar mixed convection in an inclined semicircular duct under buoyancy assisted and opposed conditions. International Journal of Heat and Mass Transfer, vol. 43, no. 7, p. 1103-1111, D0I:10.1108/09615530910930946.

[17] Mahian, O., Kianifar, A., Sahin, A.Z., Wongwises, S. (2014). Entropy generation during Al203/water nanofluid flow in a solar collector: Effects of tube roughness, nanoparticle size, and different thermophysical models. International Journal of Heat and Mass Transfer, vol. 78, p. 64-75, D0l:10.1016/j. ijheatmasstransfer.2014.06.051.

[18] Akbari, M., Behzadmehr, A., Shahraki, F. (2008). Fully developed mixed convection in horizontal and inclined tubes with uniform heat flux using nanofluid. International Journal of Heat and Fluid Flow, vol. 29, no. 2, p. 545-556, D0l:10.1016/j. ijheatfluidflow.2007.11.006.

[19] Cimpean, D.S., Pop, I. (2012). Fully developed mixed convection flow of a nanofluid through an inclined channel filled with a porous medium. International Journal of Heat and Mass Transfer, vol. 55, no. 4, p. 907-914, D0l:10.1016/j. ijheatmasstransfer.2011.10.018.

[20] Allahyari, Sh., Behzadmehr, A., Hosseini Sarvari, S.M. (2011). Conjugate heat transfer of laminar mixed convection of a nanofluid through an inclined tube with circumferentially non-uniform heating. Nanoscale Research Letters, vol. 6, DOI:10.1186/1556-276X-6-360.

[21] Mansour, R.B., Galanis, N., Nguyen, C.T. (2011). Experimental study of mixed convection with water-Al203 nanofluid in inclined tube with uniform wall heat flux. International Journal of Thermal Sciences, vol. 50, no. 3, p. 403-410, D0l:10.1016/j. ijthermalsci.2010.03.016.

[22] Pirhayati, M., Akhavan-Behabadi, M.A., Khayat, M. (2012). Pressure drop of CuO-base oil nanofluid flow inside an inclined tube. International Journal of Advances in Engineering \& Technology, vol. 5, no. 1, p. 122-129.

[23] Derakhshan, M.M., Akhavan-Behabadi, M.A. (2015). An empirical study on fluid properties and pressure drop of nanofluid flow inside inclined smooth and microfin tubes. International Communications in Heat and Mass Transfer, vol. 65, p. 111-116, D0l:10.1016/j. icheatmasstransfer.2015.04.013.

[24] Maré, T., Galanis, N., Voicu, I., Miriel, J. (2006). Experimental analysis of mixed convection in inclined tubes. Applied Thermal Engineering, vol. 26, no. 14-15, p. 1677-1683, DOI:10.1016/J.applthermaleng.2005.11.011.

[25] Ghaffari, O., Behzadmehr, A., Ajam, H. (2010). Turbulent mixed convection of a nanofluid in a horizontal curved tube using a two-phase approach. International Communications in Heat and Mass Transfer, vol. 37, no. 10, p. 1551-1558, D0I:10.1016/j.icheatmasstransfer.2010.09.003.

[26] Maninnen, M., Taivassalo, V., Kallio, S., (1996). On the Mixture Model for Multiphase Flow. VTT Energy, Espoo. 
[27] Schiller, L., Naumann, A. (1935). A Drag Coefficient Correlation, Z. Ver. Deutsch. Ing, vol. 77, p. 318-320.

[28] Launder, B.E., Spalding, D.B. (1972). Lectures in Mathematical Models of Turbulence, Academic Press, London.

[29] Hussein, A.M., Sharma, K.V., Bakar, R.A., Kadirgama, K. (2013). The effect of nanofluid volume concentration on heat transfer and friction factor inside a horizontal tube. Journal of Nanomaterials, vol. 2013, DOl:10.1155/2013/859563.

[30] Pak, B.C., Cho, Y.I., (1998). hydrodynamic and heat transfer study of dispersed fluids with submicron metallic oxide particles. Experimental Heat Transfer: A Journal of Thermal Energy Generation, Transport, Storage, and Conversion, vol. 11, no. 2, p. 151-170, Dol:10.1080/08916159808946559.

[31] Chon, C.H., Kihm, K.D., Lee, S.P., Choi, S.U.S. (2005). Empirical correlation finding the role of temperature and particle size for nanofluid (Al203) thermal conductivity enhancement. Applied Physics Letters, vol. 87, D0I:10.1063/1.2093936.

[32] Masoumi, N., Sohrabi, N., Behzadmehr, A. (2009). A new model for calculating the effective viscosity of nanofluids. Journal of Physics D: Applied Physics, vol. 42, D0l:10.1088/00223727/42/5/055501.

[33] Khanafer, Kh., Vafai, K., Lightstone, M., (2003). Buoyancydriven heat transfer enhancement in a two-dimensional enclosure utilizing nanofluids. International Journal of
Heat and Mass Transfer, vol. 46, no. 19, p. 3639-3653, DOl:10.1016/S0017-9310(03)00156-X.

[34] Gnielinski, V., Sruher, K. (1975). Neue Gleichungen für den Wärme- und Stoffübergang in turbulent durchströmten Rohren und Kanälen, Forschung Ingenieurwesen, vol. 41, p. 8-16, DOI:10.1007/BF02559682.

[35] Wusiman, K.E.B.J., Chung, H.S., Md, J.N., Handry, A., Eon., Y.S., Kim, J,H., Jeong, H.M. (2013). Heat transfer characteristics of nanofluid through circular tube. Journal of Central South University, vol. 20, no. 1, p. 142-148, Dol:10.1007/s11771013-1469-z.

[36] Torii, S. (2010). Turbulent heat transfer behavior of nanofluid in a circular tube heated under constant heat flux. Advances in Mechanical Engineering, D0I:10.1155/2010/917612.

[37] Bergman, Th.L., Lavine, A.S., Incropera, F.P., DeWitt, D.P. (2011). Fundamentals of Heat and Mass Transfer, $7^{\text {th }}$ edition, Wiley \& Sons, Hoboken

[38] Allahyari, Sh., Behzadmehr, A., Hosseini Sarvari, S.M. (2011). Conjugate heat transfer of laminar mixed convection of a nanofluid through a horizontal tube with circumferentially non-uniform heating. International Journal of Thermal Sciences, vol. 50, no. 10, p. 1963-1972, Dol:10.1016/j. ijthermalsci.2011.03.025. 